\title{
Optimum Feeding Rate for The Sub-adult Olive Flounder, Paralichthys olivaceus, Fed Practical Extruded Pellets at Optimum Water Temperature
}

\author{
Seung-Jun Shin ${ }^{1}$, Sungchul C. Bai ${ }^{2}$, Kyeong-Jun Lee ${ }^{3}$, Jeong-Dae Kim ${ }^{1}$, and Sung-Sam Kim ${ }^{4 *}$ \\ ${ }^{1}$ College of Animal Life Sciences, Kangwon National University, Chuncheon 24341, South Korea \\ ${ }^{2}$ Department of Marine Bio-Materials and Aquaculture, Pukyong National University, Busan 608-737, South Korea \\ ${ }^{3}$ Department of Marine Life Science, Jeju National University, Jeju 690-756, South Korea \\ ${ }^{4}$ Aquafeed R\&D Center, CJ CheilJedang Feed Semarang, Batang 51281, Indonesia \\ ${ }^{*}$ Corresponding author: sungsam.kim@cj.net
}

Received: 31 May 2018; Accepted: 23 July 2018

\begin{abstract}
Seung-Jun Shin, Sungchul C. Bai, Kyeong-Jun Lee, Jeong-Dae Kim, and Sung-Sam Kim. 2018. Optimum Feeding Rate for The Sub-adult Olive Flounder, Paralichthys olivaceus, Fed Practical Extruded Pellets at Optimum Water Temperature. Aquacultura Indonesiana, 19 (2): 57-64. We investigated the effects of feeding rate on the growth, blood components, and histology of the growing olive flounder (Paralichthys olivaceus). We determined the optimum feeding rate (initial fish mean weight $=525.3 \pm 7.12 \mathrm{~g}$ ) at the optimum water temperature. Two replicate groups of fish were fed a commercial diet at rates of $0 \%, 0.2 \%$, $0.4 \%, 0.6 \%$, and $0.8 \%$ (i.e., to satiation) of body weight (BW) per day. The feeding trial was conducted using a flow-through system, with ten of 1.2 -metric-ton aquaria receiving filtered seawater between 20.5 and $24.5^{\circ} \mathrm{C}$, for 3 weeks. Weight gain (WG) and specific growth rate (SGR) were significantly greater in fish fed with satiation at $0.8 \% \mathrm{BW} /$ day compared to fish fed at $0.2 \% \mathrm{BW} /$ day, and with unfed fish. These parameters were negative, and significantly lower, in the starved fish compared to the fish fed the experimental diet, for all feeding rates. There were no significant differences in WG and SGR among fish fed at $0.2 \%, 0.4 \%$, and $0.6 \% \mathrm{BW} / \mathrm{day}$, and among those fed at $0.4 \%, 0.6 \%$ and $0.8 \%$ of BW/day. The histological changes in tissues were not significant in the hepatopancreas, kidney, or anterior intestine of fish fed at $0 \%, 0.4 \%$, and $0.8 \%$ of BW/day. Broken-line regression analysis based on weight gain demonstrated that the optimum feeding rate for an olive flounder weighing $525 \mathrm{~g}$ was $0.70 \% \mathrm{BW} /$ day at optimum water temperature.
\end{abstract}

Keywords: Broken-line regression analysis; Feeding rate; Olive flounder; Optimum water temperature

\section{Introduction}

Moist pellet primarily made of raw fish, has been used as feed for culture of olive flounder in Korea. This is a problem for several reasons because unstable supply of raw fish, increased storage cost, and heavy self-pollution resulting from the thawing of raw fish to make moist pellet and leaching of nutrients from moist pellet when fed to fish. In addition, the price of raw fish has been increased due to its high demand with large scale development of marine fish aquaculture system in the country. Therefore, for further expansion of flounder farming, it is essential to employ formulated artificial dry feeds such as extruded pellet which can support reasonable growth of fish.

Optimum feeding rates vary with feeding frequency, the nutrient content of the feed, the fish species and size, and water temperature and other water-quality parameters. Channel catfish fed $36 \%$ protein gained more weight compared to those fed $30 \%$ protein, when both were fed to approximately $75 \%$ satiation, the weight gain did not differ (Minton, 1978). This illustrates the relationship between the feeding rate and nutrient (protein) content of the diet. A similar result showed by Li and Lovell (1992a, 1992b), also in channel catfish.

The olive flounder (Paralichthys olivaceus) is one of the most commercially important marine aquaculture species in Korea, and was ranked first for marine finfish aquaculture production in 2014 (Statistics Korea, 2014). The olive flounder is very popular and highly valued by Koreans due to its high dressing percentage and pleasant taste. To optimize growth, cost of production and product quality, the optimum feeding rates for various sizes of this species need to be established.

Feeding costs account for the major portion of aquaculture production costs, rendering feed management one of the most important determinants of viability and productivity for any 
commercial aquaculture operation. Diet costs can represent between $30 \%$ and $70 \%$ of the total operating cost of an aquaculture enterprise: the proportion increases commensurate with the intensity of the operation (Webster et al., 2001). Feed intake is perhaps the principal factor affecting the growth rate of fish (Li et al., 2004); several studies have demonstrated that growth correlates to food intake (Mihelakakis et al., 2002; Cho et al., 2007; Kim et al., 2007; Ozorio et al., 2009). Ensuring an adequate supply of nutritionally balanced feed is critical for optimum growth, survival, disease immunity, dress-out yield, and the organoleptic properties of the flesh. If the feed supply is inadequate, reduced growth and survival rates will result. Conversely, overfeeding increases fish production costs, and reduces profit, due to the increased cost of feed and deterioration of water quality, which can eventually reduce the growth of fish. The food application rate does not necessarily equate to the food consumption rate in large-scale commercial systems, because a significant and unknown proportion of administered food may not be eaten (Yamada, 1985).

Feeding rates have been determined in various species of fish at various stages of growth (Hung et al., 1993; Mihelakakis et al., 2002; Fiogbe and Kestemont, 2003). Feeding rates are influenced by various factors, including fish size, and decrease commensurate with the growth of fish. Fiogbe and Kestemont (2003) reported that optimum feeding rates, for Eurasian perch (Perca fluviatilis), decreased by $7.4 \%, 5.1 \%, 4.5 \%$ and $2.2 \%$ biomass/day, for fish with initial weights of $0.22,0.73,1.56$ and $18.9 \mathrm{~g}$, respectively. Several studies have determined optimum feeding rates in juvenile and growing-stage olive flounders (Kim et al., 2010; Kim et al., 2011; Lee et al., 2014; Kim et al., 2014). However, optimum feeding rates in sub-adult olive flounders have not yet been determined. Therefore, this feeding trial was conducted to determine the optimum feeding rate of sub-adult olive flounder at optimum water temperature.

\section{Materials and Methods}

\section{Experimental Diets}

The commercial feed used in the feeding trial was supplied by Suhyup Feed Company Limited (Uiryeong, Gyeongsangnamdo, Republic of Korea). Feed sizes, with the corresponding proximate composition, were selected according to fish size, in line with the methods employed by farms and the recommendations of the company. The proximate composition of the experimental diet is delineated in Table 1.

Table 1. Proximate analysis of the experimental diet of the olive flounder (Paralichthys olivaceus; \% of DM basis)

\begin{tabular}{lc}
\hline Proximate composition & Content \\
\hline Dry matter (\%) & 7.04 \\
Crude protein (\%, DM) & 56.0 \\
Crude lipid $(\%, \mathrm{DM})$ & 14.3 \\
Crude ash $(\%, \mathrm{DM})$ & 11.4 \\
Gross energy $(\mathrm{MJ} / \mathrm{kg})$ & 17.6 \\
Size $(\mathrm{mm})$ & $15.0 \sim 15.4$ \\
\hline
\end{tabular}

\section{Experimental Fish and Feeding Trial}

Fish were collected from Chang-Hae Fisheries in Jeju-Do, Republic of Korea. Prior to the commencement of the experiment, fish were fed the commercial diet twice daily to apparent satiation for 1 week, to acclimate them to the experimental diet and conditions. The commercial feed used in all the feeding trials was supplied by Suhyup Feed Company Limited (Uiryeong, Gyeongsangnamdo, Republic of Korea). Three hundred fish with an initial body weight of 525.3 $\pm 7.12 \mathrm{~g}$ (mean $\pm S D$ ) were randomly distributed among 10 tanks (30 fish/tank). Each tank was then randomly assigned one of the five feeding rates: $0 \%, 0.2 \%, 0.4 \%$, and $0.6 \% \mathrm{BW} /$ day, and satiation ( $0.8 \% \mathrm{BW} /$ day). Fish were fed twice per day, at 09:00 and 16:00. The feeding trial was conducted using a flow-through system, in ten (1MT) tanks receiving filtered seawater from a central tank. The total body weight of fish, in each aquarium, was recorded every week, and the amount of diet fed to the fish was adjusted accordingly. The rearing water temperature during the experiment ranged between 20.5 and $24.5^{\circ} \mathrm{C}$. Photoperiods were maintained under conditions of natural light. Supplemental aerations were provided to maintain dissolved oxygen levels at $6.5 \pm 0.5 \mathrm{ppm}$ : salinity was maintained at $33 \pm 1 \mathrm{ppt}$.

\section{Sample Collection and Analysis}

Weight gain (WG), specific growth rate (SGR), feed efficiency (FE), protein efficiency ratio (PER), survival and whole-body proximate composition were calculated and measured at the end of the feeding trials. Blood samples were obtained from the caudal vein of 6 fish from each 
tank (12 fish per dietary treatment), using a heparinized syringe following anesthetization of the fish with tricaine methanesulfonate (MS-222) at $100 \mathrm{mg} / \mathrm{L}$. Immediately afterward, hematocrit and hemoglobin were measured using the micro hematocrit technique (Brown, 1980) and CH 100 plus blood biochemical auto analyzer (SEAC, Italy), respectively. Following measurement of whole blood, blood plasma was collected after centrifugation at $300 \times \mathrm{g}$ for $5 \mathrm{~min}$, and was stored at $-70^{\circ} \mathrm{C}$ as separate aliquots for assay of total protein, alanine aminotransferase (ALT) and aspartate aminotransferase (AST) using a blood biochemical auto analyzer. Hemoglobin was determined by an end-point method, and alanine aminotransferase and aspartate aminotransferase activities were determined using a kinetic method. The remaining six fish from each tank were sampled at the end of the feeding trial and stored at $-70^{\circ} \mathrm{C}$ for the subsequent proximate whole-body analysis, using standard methods (AOAC, 1990). The clinical signals of the fish were carefully monitored on a daily basis throughout the experiment. At the end of feeding trial, fish were autopsied and processed for histological examination. Autopsies were carried out on three randomly selected fish from each tank. All tissues and organs obtained were fixed in Bouin's solution and processed for a routine histological examination.

\section{Statistical Analysis}

All data were subjected to one-way ANOVA using the SPSS for Windows software package (ver. 11, Chicago, IL, USA). Group differences were assessed using Duncan's multiple tests. Data are presented as means $\pm S E$. The optimum feeding rate was estimated using the Broken-line regression method (Robbins, 1979).

\section{Results}

Weight gain (WG) and specific growth rate (SGR) were significantly higher in fish fed to satiation (0.8\% BW/day) compared to both those fed at $0.2 \% \mathrm{BW} /$ day and the unfed fish (Table 2). There were no significant differences in $\mathrm{WG}$ and SGR among fish fed at $0.2 \%, 0.4 \%$ and $0.6 \%$ $\mathrm{BW} /$ day, and among those fed at $0.4 \%, 0.6 \%$ and $0.8 \%$ of BW/day. WG and SGR of the unfed fish were both negative, and significantly lower, compared with fish fed the experimental diet, for all feeding rates. There were no significant differences in FE and PER for fish in all feeding conditions.

The serological characteristics of sub-adult olive flounders fed the experimental diet at different feeding rates are described in Table 3. Hematocrit was significantly higher in fish fed at $0.2 \%, 0.4 \%$ and $0.6 \% \mathrm{BW} /$ day compared to both the unfed fish and the fish fed to satiation $(0.8 \%$ $\mathrm{BW} /$ day). There were no significant differences in hematocrit among either the unfed fish or those fed to satiation, or among those fed at $0.2 \%, 0.4 \%$ and $0.6 \% \mathrm{BW} /$ day. Blood glucose was significantly higher in fish fed at $0.6 \%$ $\mathrm{BW} /$ day than in either the unfed fish or those fed at $0.2 \%$ and $0.8 \% \mathrm{BW} /$ day. There were no significant differences in hemoglobin, alanine aminotransferase, aspartate aminotransferase, or total protein, for fish in all treatment conditions.

Table 2. Effect of feeding rates on the growth performance of olive flounder (Paralichthys olivaceus) fed the experimental diet for 3 weeks ${ }^{1}$

\begin{tabular}{llllllc}
\hline & \multicolumn{2}{l}{ Diets } & & & \multicolumn{2}{c}{ Pooled SEM $^{7}$} \\
\cline { 2 - 5 } & $0 \%$ & $0.2 \%$ & $0.4 \%$ & $0.6 \%$ & $\mathrm{~S}^{2}$ & \\
\hline Initial weight (g/fish) & 525.3 & 523.2 & 522.0 & 518.7 & 537.3 & 8.73 \\
Final weight (g/fish) $_{\text {Weight gain }^{3}}$ & $393.2^{\mathrm{a}}$ & $549.4^{\mathrm{b}}$ & $575.7^{\mathrm{bc}}$ & $581.5^{\mathrm{bc}}$ & $628.7^{\mathrm{c}}$ & 27.07 \\
Specific growth rate $^{4}$ & $-20.7^{\mathrm{a}}$ & $5.0^{\mathrm{b}}$ & $10.3^{\mathrm{bc}}$ & $12.1^{\mathrm{bc}}$ & $17.0^{\mathrm{c}}$ & 4.49 \\
Feed efficiency $^{5}$ & $-1.37^{\mathrm{a}}$ & $0.29^{\mathrm{b}}$ & $0.58^{\mathrm{bc}}$ & $0.67^{\mathrm{bc}}$ & $0.92^{\mathrm{c}}$ & 0.28 \\
Protein efficiency ratio $^{6}$ & - & 102.4 & 112.7 & 111.0 & 111.8 & 8.92 \\
Survival (\%) & - & 1.83 & 2.02 & 1.99 & 2.00 & 0.16 \\
\hline
\end{tabular}

${ }^{1}$ Values are means from duplicate groups of fish; values in each row with different superscripts are significantly different $(p<0.05)$.

${ }^{2} \mathrm{~S}=$ Satiation $(0.8 \%)$.

${ }^{3}$ Weight gain $(\%)=($ final weight - initial weight $) \times 100 /$ initial weight.

${ }^{4}$ Specific growth rate $(\%)=\left(\log _{\mathrm{e}}\right.$ final wt. $-\log _{\mathrm{e}}$ initial wt. $) /$ days .

${ }^{5}$ Feed efficiency $(\%)=$ wet weight gain $(\mathrm{g}) \times 100 /$ dry feed intake $(\mathrm{g})$.

${ }^{6}$ Protein efficiency ratio $=$ wet weight gain/protein intake

${ }^{7}$ Pooled standard error of means $=\mathrm{SD} / \sqrt{ } \mathrm{n}$. 
Table 3. Effects of feeding rate on the serological characteristics of olive flounder (Paralichthys olivaceus) fed the experimental diet for 3 weeks ${ }^{1}$.

\begin{tabular}{lllllll}
\hline & Diets & \multicolumn{3}{l}{} & \multirow{2}{*}{ Pooled SEM } \\
\cline { 2 - 5 } & $0 \%$ & $0.2 \%$ & $0.4 \%$ & $0.6 \%$ & $\mathrm{~S}^{2}$ & \\
\hline Hematocrit (\%) & $21.0^{\mathrm{a}}$ & $29.5^{\mathrm{b}}$ & $29.9^{\mathrm{b}}$ & $27.6^{\mathrm{b}}$ & $22.8^{\mathrm{a}}$ & 1.22 \\
Hemoglobin (g/dL) & 5.8 & 7.4 & 7.5 & 7.4 & 6.9 & 0.26 \\
AST (U/L) & 23.6 & 45.6 & 41.5 & 40.7 & 33.9 & 3.50 \\
ALT (U/L) & 6.38 & 5.04 & 12.76 & 6.11 & 5.96 & 1.43 \\
Glucose (mg/dL) & $10.7^{\mathrm{a}}$ & $13.2^{\mathrm{ab}}$ & $22.1^{\mathrm{bc}}$ & $24.8^{\mathrm{c}}$ & $13.4^{\mathrm{ab}}$ & 2.10 \\
Total protein (mg/dL) & 3.4 & 4.1 & 3.3 & 2.8 & 4.1 & 0.23 \\
\hline
\end{tabular}

Values are means from duplicate groups of fish; values in each row with different superscripts are significantly different $(p<0.05)$.

${ }^{2} \mathrm{~S}=$ Satiation $(0.8 \%)$.

${ }^{3}$ AST $=$ Aspartate aminotransferase.

Unit per liter $(\mathrm{U} / \mathrm{L})=$ the amount of enzyme which oxidizes one $\mu \mathrm{mol} / \mathrm{L}$ of $\mathrm{NADH}$ per minute.

${ }^{4} \mathrm{ALT}=$ Alanine aminotransferase.

${ }^{5}$ Pooled standard error of means $=\mathrm{SD} / \sqrt{ } \mathrm{n}$

Table 4 displays the whole-body proximate composition of olive flounders fed the experimental diet. Although there were significant differences in all analyzed parameters, there were no clear trends. There were no clear correlation between feeding rate and whole body composition of olive flounders.

Histological changes in the tissues of fish fed the experimental diet at different feeding rates are illustrated in Figure 2. Differences in the condition of the hepatopancrease, kidney and anterior intestine of fish fed at $0 \%, 0.4 \%$ and $0.8 \% \mathrm{BW} /$ day were minimal.

Broken line regression analysis, for WG, indicated that the optimum feeding rate for a 525$\mathrm{g}$ sub-adult olive flounder is $0.70 \% \mathrm{BW} /$ day (Figure 1).

Table 4. Effect of feeding rate on the whole-body composition of olive flounder (Paralichthys olivaceus) fed the experimental diet for 3 weeks $(\%)^{1}$.

\begin{tabular}{lllllll}
\hline & Diets & & & & \multirow{2}{*}{ Pooled SEM $^{3}$} \\
\cline { 2 - 5 } & $0 \%$ & $0.2 \%$ & $0.4 \%$ & $0.6 \%$ & $\mathrm{~S}^{2}$ & \\
\hline Moisture & $74.4^{\mathrm{ab}}$ & $72.8^{\mathrm{a}}$ & $74.0^{\mathrm{ab}}$ & $72.8^{\mathrm{a}}$ & $74.7^{\mathrm{b}}$ & 0.29 \\
Crude protein & $67.8^{\mathrm{b}}$ & $70.2^{\mathrm{c}}$ & $64.9^{\mathrm{a}}$ & $68.0^{\mathrm{b}}$ & $69.2^{\mathrm{ab}}$ & 0.61 \\
Crude lipid & $18.9^{\mathrm{b}}$ & $19.2^{\mathrm{b}}$ & $17.3^{\mathrm{a}}$ & $20.6^{\mathrm{c}}$ & $17.4^{\mathrm{a}}$ & 0.42 \\
Crude ash & $12.2^{\mathrm{a}}$ & $11.6^{\mathrm{a}}$ & $12.3^{\mathrm{a}}$ & $14.0^{\mathrm{b}}$ & $12.6^{\mathrm{a}}$ & 0.29 \\
\hline
\end{tabular}

Values are means from duplicate groups of fish; values in each row with different superscripts are significantly different $(p<0.05)$.

${ }^{2} \mathrm{~S}=$ Satiation $(0.8 \%)$.

${ }^{3}$ Pooled standard error of means $=\mathrm{SD} / \sqrt{ } \mathrm{n}$

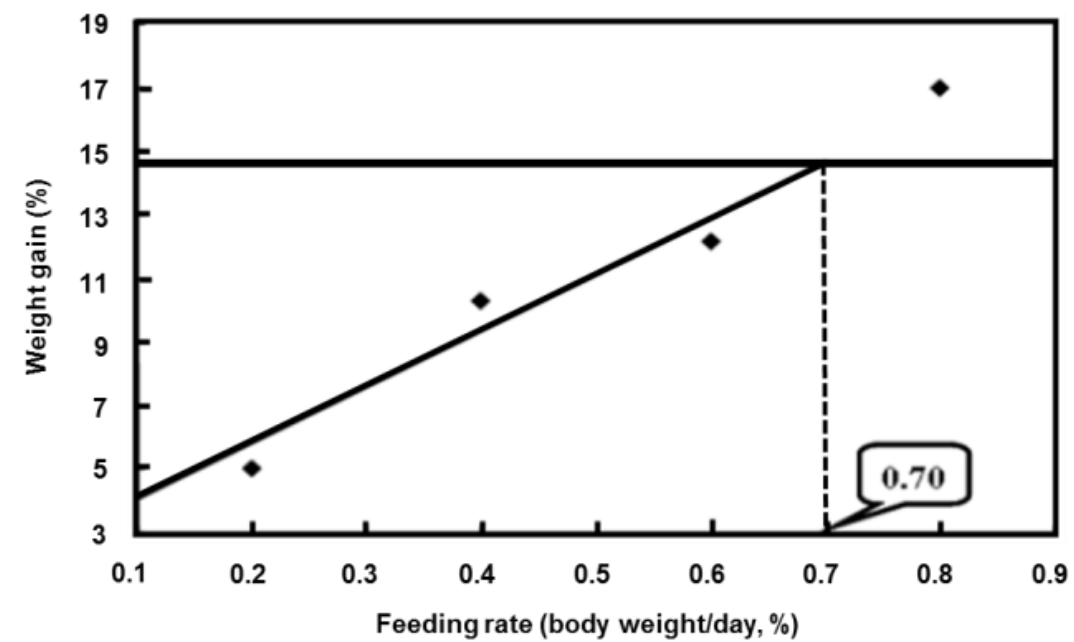

Figure 1. Broken-line regression analysis of weight gain (\%) according to feeding rate. Each point represents the average of two groups of fish. The optimum feeding rate for weight gain was $0.70 \%$ body weight/day. 


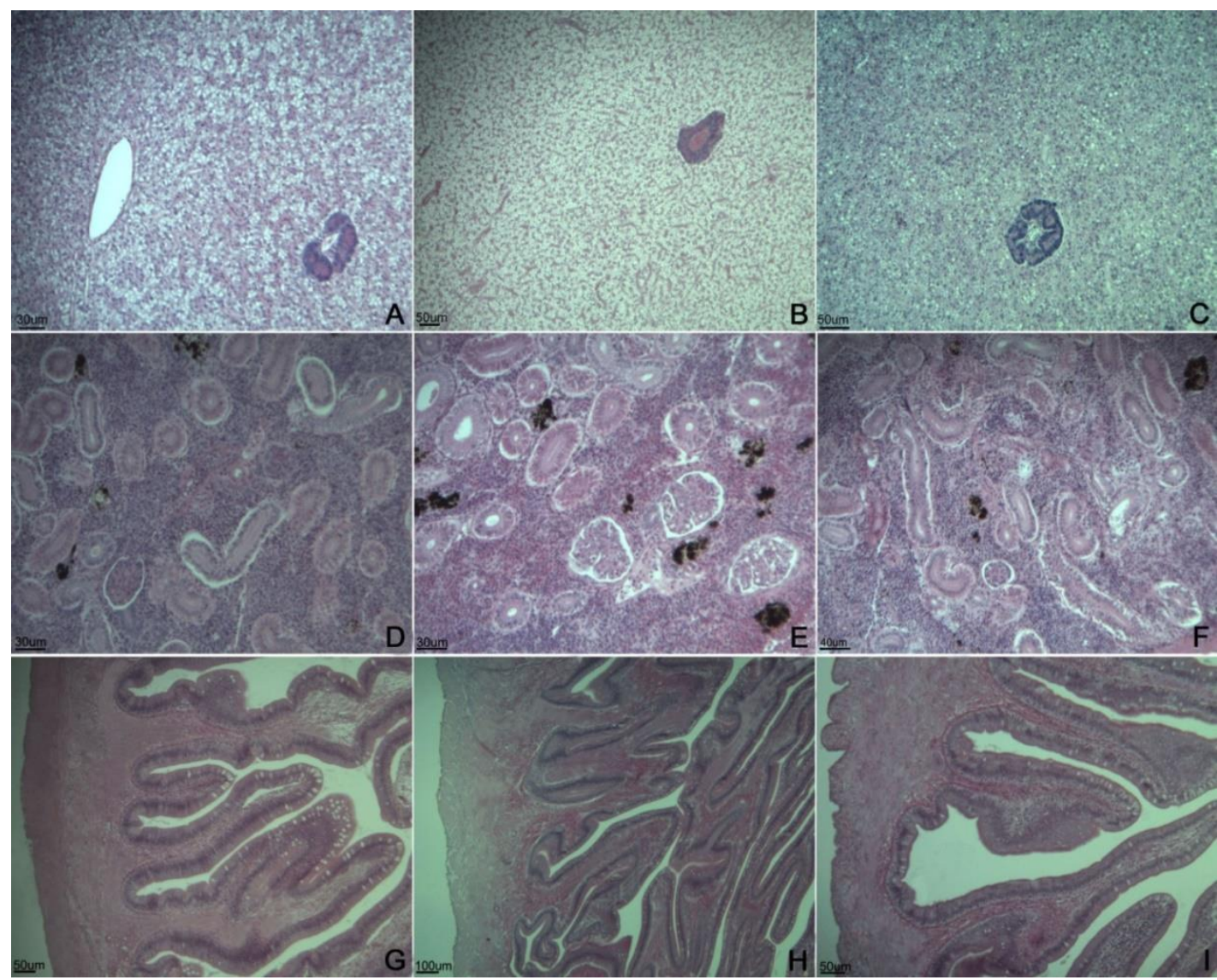

Figure 2. Histological changes of the hepatopancreas, kidney and anterior intestine of olive flounder (Paralichthys olivaceus) fed the experimental diet for 3 weeks. A, D and G: $0 \%$ group

(A:hepatopancreas, D: kidney, and G: anterior intestine), B, E and H: 0.4\% group (B: hepatopancreas, E: kidney, and H: anterior intestine), C, F and I: S (satiation, 0.8\%) group (C: hepatopancreas, F: kidney, and I: anterior intestine).

\section{Discussion}

The present study demonstrated that growth in olive flounders improves in accordance with feeding rate, at the optimum water temperature. Weight gain and growth rate increased with feeding rate, up to the level of satiation (Table 2). Growth has been reported to increase commensurate with feeding rate in several fish species (Adebao et al., 2000; $\mathrm{Ng}$ et al., 2000; Mihelakakis et al., 2002). The optimum feeding rate for a sub-adult olive flounder $(525 \mathrm{~g})$ was $0.70 \%$ body weight per day, based on weight gain indexed by broken-line regression analysis (Figure 1). Fish appear to continuously increase in weight commensurate with feeding rate up to the level of satiation, although this increase may not correspond with incremental feed consumption. Continuous weight gain in response to increased feeding rate has been reported in blackspot seabream (Pagellus bogaraveo; Ozorio et al., 2009); olive flounder (P. olivaceus; Cho et al., 2007); white sturgeon (Acipenser transmontanus;
Deng et al., 2003); and gilthead sea bream (Spurus aurata; Mihelakakis et al., 2002), among other species. However, the improvement in growth performance of fish fed at a rate below satiation varied according to fish size.

Feed utilization plateaued at certain feeding rates. Maximum feed efficiency has been reported for feeding rates below those required for maximum growth (Brett and Groves, 1979). At low feeding rates, fish tend to optimize their digestion to extract nutrients more efficiently (Zoccarato et al., 1994; Van Ham et al., 2003). This implies an inverse relationship between feeding rate and feed efficiency. The peak in feed efficiency in the present study could be explicable on the basis of greater weight gain $v s$. the incremental feed intake observed for feeding rates below the peak value. However, beyond the peak value, fish could not efficiently utilize the additional food, leading to a drop in feed efficiency.

Table 3 displays the serological characteristics of sub-adult olive flounders fed 
the experimental diet at different feeding rates. Hematocrit levels were significantly higher in fish fed at $0.2 \%, 0.4 \%$ and $0.6 \% \mathrm{BW} /$ day, compared to both the unfed fish and the fish fed to satiation $(0.8 \% \mathrm{BW} /$ day $)$. Hematocrit levels are frequently used to indicate the health and immunity status of fish. There were no significant differences in hematocrit levels between the unfed fish and those fed to satiation, nor between those fed at $0.2 \%, 0.4 \%$, and $0.6 \% \mathrm{BW} /$ day. The results indicate that inadequate feeding, or overfeeding, could affect the health and immunity status of fish: it appears that adequate feed supplies are vital for the optimum growth, health, and immunity.

The whole-body proximate composition, of sub-adult olive flounders fed the experimental diet, is delineated in Table 4. There were no clear trends in any of feeding rate categories. Cho et al. (2006) observed no relationship between feeding rate and the proximate composition of olive flounders for any parameter other than crude protein. The differences in whole-body composition according to feeding rate cannot be explained by the present results. Whole-body proximate composition appears to be a weak determinant of feeding rate.

Histological changes associated with the different feeding rates are displayed in Figure 2. There were minimal differences in the response of the hepatopancreas, kidney, and anterior intestine of fish according to feeding rate. All tissues, of fish fed at $0 \%, 0.4 \%$, and $0.8 \%$ BW/day, were in good condition. Kim et al. (2014) reported that histological changes in fish fed at $0.6 \% \mathrm{BW} /$ day indicate that this group was in the best condition; minimal differences were observed in the tissues of fish fed at $0.6 \%$, compared with those fed at $0 \%$ and $1.0 \%$ BW/day, at the optimum water temperature. Similar results have also been reported for olive flounders at various growth stages (Lee et al., 2014; Kim et al., 2014).

In the present study, increased feeding rates improved the growth performance of the sub-adult olive flounder; similar results have been reported for many other fish species ( $\mathrm{Ng}$ et al., 2000; Mihelakakis et al., 2002; Lee et al., 2014; Kim et al., 2104). At all growth stages, optimum feeding rates decreased with fish size. This observation is in agreement with previous studies of various species (Skalli et al., 2004; Hatlen et al., 2005; Sweilum et al., 2005). Fish growth rates decrease with age, and by extension greater size. This implies that small fish have an increased demand for food to satisfy their high metabolic rates.

\section{Conclusion}

A broken-line regression analysis of weight gain indicated that the optimum feeding rate of olive flounders weighing $525 \mathrm{~g}$ was $0.70 \%$ BW per day at optimum water temperature (Fig. 1). Future studies should focus on water temperature (low and high), adult stages of greater duration, and olive flounders weighing more than $1 \mathrm{~kg}$.

\section{Acknowledgement}

This research was supported by the 2018 scientific promotion funded by Jeju National University.

\section{References}

Adebao, O.T., A.M. Balogun, and O.A. Fagbenro. 2000. Effects of feeding rates on growth, body composition and economic performance of juvenile clariid catfish hybrid (female Clarias gariepinus $\times$ male Heterobranchus bidorsalis). J. Aquac. Trop.,15:109-117.

AOAC. 1990. Official Methods of Analysis. 15th edn. Association of Official Analytical Chemists, Arlington, Virginia, U.S.A.

Brett, J.R. and T.D.D. Groves. 1979. Bioenergetics. In: Hoar, W.S., J.J. Randall and J.R. Brett (Eds.), Fish Physiology. Academic Press, New York, USA, pp. 279-352.

Brown, B.A. 1980. Routine hematology procedure. In: Brown, B.A. (Ed.), Hematology: Principles and Procedures. Lea and Febiger, Philadelphia, Pennsylvania, USA, pp. 71-112.

Cho, S.H., S.M. Lee, B.H. Park, and S.M. Lee. 2006. Effect of feeding ratio on growth and body composition of juvenile olive flounder, Paralichthys olivaceus, fed extruded pellets during the summer season. Aquaculture, 251: 78-84.

Cho, S.H., S.M. Lee, B.H. Park, S.C. Ji, C.Y. Choi, J.H. Lee, Y.C. Kim, and S.Y. Oh. 2007. Effect of daily feeding ratio on growth and body composition of subadult olive flounder, Paralichthys olivaceus, fed an extruded diet during the summer season. $J$. World Aquac. Soc., 38: 68-73.

Deng, D.F., S. Koshio, S. Yokoyama, S.C. Bai, Q. Shao, Y. Cui, and S.S.O. Hung. 2003. Effects of feeding rate on growth performance of white sturgeon (Acipenser transmontanus) larvae. Aquaculture, 217: 589-598. 
Fiogbe, E.D. and P. Kestemont. 2003. Optimum daily ration for Eurasian perch Perca fluviatilis L. reared at its optimum growing temperature. Aquaculture, 216: 243-252.

Hatlen, B., B. Grisdale-Helland, and S.J. Helland. 2005. Growth, feed utilization and body composition in two size groups of Atlantic halibut (Hippoglossus hippoglossus) fed diets differing in protein and carbohydrate content. Aquaculture, 249: 401-408.

Hung, S.S.O., P.B. Lutes, A.A. Shqueir, and F.S. Conte. 1993. Effect of feeding rate and water temperature on growth of juvenile white sturgeon (Acipenser transmontanus). Aquaculture, 115: 297-303.

Kim, K.D., Y.J. Kang, K.W. Kim, and K.M. Kim. 2007. Effects of feeding rate on growth and body composition of juvenile flounder, Paralichthys olivaceus. J. World Aquac. Soc., 38: 169-173.

Kim, K.W., N.Y. Hwang, M.H. Son, K.D. Kim, J.H. Lee, Y. Liu, Y.H. Yun, G.H. Park, S.S. Kim, K.J. Lee, and S.C. Bai. 2010. Optimum feeding rates in juvenile olive flounder Paralichthys olivaceus fed practical expanded pellet at low and high water temperatures. Kor. J. Fish Aquat. Sci., 44: 345-351.

Kim, K.W., S.S. Kim, J.W. Kim, M.H. Son, M.H, K.D. Kim, S.C. Bai, and K.J. Lee. 2011. Effect of feeding rate and pellet watersoaking on growth, blood components, and histology of olive flounder Paralichthys olivaceus. Kor. J. Fish Aquat. Sci., 44: 490498.

Kim, S.S., K.W. Kim, K.D. Kim, B.J. Lee, H.S. Han, J.W. Kim, S.C. Bai, and K.J. Lee. 2014. Optimum feeding rate in growing olive flounder Paralichthys olivaceus fed practical extruded pellet at optimum water temperature $\left(21^{\circ} \mathrm{C}\right)$. J. Fish Mar. Sci. Edu., 26: 787-795.

Lee, J.H., S.S. Kim, K.W. Kim, K.D. Kim, B.J. Lee, J.H. Lee, H.S. Han, J.W. Kim, S.Y. Kim, and K.J. Lee . 2014. Optimum feeding rate in growing olive flounder Paralichthys olivaceus fed practical expanded pellet at optimum water temperature. Kor. J. Fish Aquat. Sci., 47: 234-240.

Li, M. and R.T. Lovell. 1992a. Comparison of satiate feeding and restricted feeding of channel catfish with various concentrations of dietary protein in production ponds. Aquaculture, 103: 165-175.

Li, M. and R.T. Lovell. 1992b. Effect of dietary protein concentration on nitrogenous waste in intensively fed catfish ponds. J. World Aquac. Soc., 23: 122-127.

Li, M.H., B.B. Manning, and E.H. Obinson. 2004 Effect of daily feed intake on feed efficiency of juvenile channel catfish. North American Journal Aquaculture, 29: 156161.

Mihelakakis. A., C. Tsolkas, and T. Yoshimatsu. 2002. Optimization of feeding rate for hatchery-produced juvenile gilthead sea bream, Sparus aurata. J. World Aquac. Soc., 33: 169-175.

Minton, RV. 1978. Responses of channel catfish fed diets of two nutrient concentrations at three rates in ponds. Master's Thesis, Auburn University, Auburn, Al, USA.

Ng, W.K., K.S. Lu, R. Hashim, and A. Ali. 2000. Effects of feeding rate on growth, feed utilization and body composition of a tropical bagrid catfish. Aquacult. Int., 8: 1929.

Ozorio, RODA, C. Andrade, VMFA. Timoteo, LEC. Conceicao, and LMP. Valente. 2009. Effects of feeding levels on growth response, body composition, and energy expenditure in blackspot seabream, Pagellus bogaraveo, Juveniles. J. World Aquac. Soc., 40: 95-103.

Robbins, K.R., H.W. Norton, and D.H. Baker. 1979. Estimation of nutrient requirements from growth data. J. Nutr., 109: 1710-1714.

Skalli. A., M.C. Hidalgo, E. Abellan, M. Arizcun, and G. Cardenete. 2004. Effects of the dietary protein/lipid ratio on growth and nutrient utilization in common dentex (Dentex dentex L.) at different growth stages. Aquaculture, 235: 1-11.

Statistics Korea, 2014. Statistic Database for Aquaculture production. http://kostat.go.kr. Accessed July 02, 2014.

Sweilum, M.A., M.M. Abdella, and S.A.S. El-Din. 2005. Effect of dietary protein-energy levels and fish initial sizes on growth rate, development and production of Nile tilapia, Oreochromis niloticus L. Aquac. Res., 36: 1414-1421.

Van Ham, E.H., M.H.G. Berntssen, A.K. Imsland, A.C. Parpoura, S.E. Wenderlaar Bonger, and S.O. Stefansson. 2003. The influence of temperature and ration on growth, feed conversion, body composition and nutrient retention of juvenile turbot (Scohthalmus maximus). Aquaculture, 217: 547-558.

Webster, C.D., K.R. Thompson, A.M. Morgan, E.J. Grisby, and S. Dasgupta. 2001. Feeding frequency affects growth, not fillet composition, of juvenile sinshine bass, Morone chrysops $\times$ M. saxatilis, grown in cages. J. World Aquac. Soc., 32: 79-88.

Yamada, R. 1985. Pond production systems. In: Lannan J.E., R.O. Smitherman, and G. Tchobanoglous (Eds.), Stocking Practices in Pond Fish Culture. Oregon State University Press, Corvallis, Oreogon, USA, pp. 85-96. 
Zoccarato. I., G. Benatti, M.L. Bianchini, M. Boccignone, A. Conti, R. Napolitano, and G.B. Palmegiano. 1994. Differences in performance, flesh composition and water output quality in relation to density and feeding levels in rainbow trout Oncorhynchus mykiss (Walbaum), farming. Aquac. Res., 25: 639-647. 